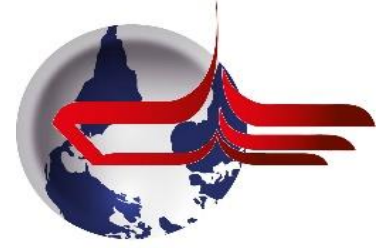

TURK-TES

Turkish Journal of Educational Studies, 6 (3) Ekim 2019

Research Article / Araştırma Makalesi

Received/Geliş: 19.05. 2019 Accepted/Kabul: 08.10.2019 Published/Yayınlanma: 25.10.2019

\title{
Cinsiyete Göre Öfke Düzeyinin İncelenmesi: Türkiye’de Yapılan Tezler Üzerine Bir Meta-Analiz Çalışması
}

\begin{abstract}
Abdullah MANAP ${ }^{1}$
Ali KIŞ***

$\ddot{O} \mathbf{z}$

$\mathrm{Bu}$ araştırma, cinsiyete göre öfke düzeyini incelemek amacıyla yapılmış olan bir meta-analiz çalışmasıdır. Araştırmada 101 çalışma içerisinden cinsiyet değişkenini kullanan ve analiz sonuçlarını teze dahil eden 24 çalışma kullanılmıştır. Örneklem sayısı 3495'i erkek, 3932'i kadın olmak üzere toplam 7427 bireyi kapsamaktadır. Araştırmaya sürekli öfke-öfke ifade tarz ölçeğini kullanan tezler dahil edilmiştir. Meta-analiz çalışmasına dahil edilen 24 tez çalışmasındaki bulgulardan elde edilen kadın ve erkeklerin örneklem sayıları, ortalama puanlar, standart sapma, F, t ve p değerleri kullanılmıştır. Elde edilen analiz sonuçlarına göre erkeklerin lehine önemsiz düzeyde ( $\mathrm{d}=-0.02)$ bir genel etki büyüklüğü bulunmuştur.
\end{abstract}

Anahtar Kelimeler: Öfke, Öfke Düzeyi, Meta-Analiz

\section{Analyzing of Anger by Gender: Meta-Analysis Study on The Theses in Turkey}

\begin{abstract}
This research is a meta-analysis work that aimed at analyzing the level of anger according to gender. In the research 24 studies were used among 101 studies that using gender variable and the results of the analysis have been included to the thesis. The sample consist of 7427 individuals of which 3495 of them male and 3932 female. Trait Anger and Anger Styles Scale theses were included to the research. Sample numbers of men and women, overage score, standard deviation and $\mathrm{F}, \mathrm{t}$ and $\mathrm{p}$ values were used in the results that obtained from 24 thesis which included in Meta-analysis work. According to analysis results, a general effect size was found at an insignificant level $(\mathrm{d}=$ $0.02)$ in favor of men.
\end{abstract}

Keywords: Anger, Anger Styles, Meta Analysis

\footnotetext{
${ }^{1}$ Öğretim Görevlisi, Batman Üniversitesi, Meslek Yüksekokulu, Çocuk Gelişimi Bölümü, Batman, Türkiye, abdullahmanap@batman.edu.tr

${ }^{* *}$ Doçent Dr., İnönü Üniversitesi, Eğitim Fakültesi, Eğitim Bilimleri Bölümü, Malatya, Türkiye, ali.kis@inonu.edu.tr
} 


\section{Giriş}

İnsanlık tarihinin başlangıcından beri tüm toplumlarda; öfkenin bireyin kendine ve çevresine zararları ile ilgili sayısız hikayeler, efsaneler, atasözleri v.b. sözlü ve yazılı kaynak vardır. Öfke ile ilgili sözlü ve yazılı kaynaklar her kültürde kendine özgü yaklaşımlarla karşımıza çıksa da ortak paydada öfke düzeyinin yüksek oluşu olumsuzluk olarak algılanır. Bunlara ek olarak dini inançların birçoğu öfkeyi ayrıca ele alarak; öfkenin olumsuzluk yaratan bir durum olduğunu, kişinin kendine ve çevresine zarar verdiğini ve ikili ilişkilerde etkisinin olduğunu anlatmaya çalışmışlardır. Bunlara rağmen yapılan çalışmalar, müdahale programları, eğitimler, dini öğretiler, kanunlar ve yasalara karşın yüzyıllardır öfke problemi çeşitli şekillerde devam etmektedir.

Bedell ve Lennox'a (1997) göre bireyler, beklentilerini karşılanmadığında ve var olan beklentilerini karşılamak istediklerinde öfkelenir. Öfke, sosyal etkileşimi azaltan ve sosyal etkileşimin kalitesini olumsuz etkileyen bir duygudur (Gallo ve Smith, 1999). Usta (2013) öfkenin tanımını; bireyler istekleri engellendiğinde yetersizlik, değersizlik vb. duygular yaşamaktadırlar; buna bağlı olarak kendini engelleyen ve sınırlayanlara karşı tehdit içeren bir tepki gösterirler şeklinde yapmıştır. TDK'ya (2015) göre öfke; engelleme, incinme veya gözdağı karşısında gösterilen saldırganlık tepkisi, kızgınlık, hışım, hiddet, gazap olarak tanımlanmıştır. Deniz'e (2011) göre vurma ve öfke krizleri oyun çağında ve bebeklikte öfkenin ortak ifadesidir ancak ergenlikte şiddete eğilimli olma algılanan anne-baba tutumlarına göre de değişebilmektedir (Demir ve Kumcağız, 2015). Bireyin yeterli sosyal etkileşim imkanlarının bulunmaması da onların duygularını olumsuz bir şekilde etkileyebilir (Yavuz, 2019) Ayrıca tekmeleme, bağırma ve nefes kesilmesi gibi davranışlar öfke nöbetlerinin düzeyini gösterir. Öfkenin tanımı ve başlama yaşı incelendiğinde; yaşam süreci içerisindeki doğal bir duygu olduğu söylenebilir (Howells ve Day, 2003). Ancak, düzeyi ve sürekliliği kişinin kendisine ve çevresine problem yaratabilmektedir. Öfke duygusuna sebep olan engellenme, suçluluk ve utanç duygusu, düşük benlik saygısı, kıskançlık, hayal kırıklığı, kötü anılar ve rekabet gibi içsel nedenler; kalıcı hastalıklar, alkol ve uyuşturucu, tehdit edilmek, saldırıya uğramak, aldatılmak, değersiz görülmek, umursanmamak, cinsel taciz ve ölüm gibi dışsal nedenler bulunmaktadır (Karslı, 2012; Ozmen, Akuzum, Zincirli ve Selçuk, 2016).

Birçok koşulda olumsuzluk yaratan öfke; düzeyi açısından bölgesel, kültürel ve dini farklılıklar gösterebilir. Bir takım dini tutumlar öfkelenilen durumları değiştireceği gibi bazı durumlara göre öfke düzeyini de etkileyebilir. Kültürel farkl1lıklara göre öfkelenilecek tutum ve davranışlar farklılık gösterebilir (Soysal, Can ve Kılıç, 2009). Örneğin; taşrada toplu taşıma araçlarında yaşına bakılmaksızın kadına yer vermemek öfkelenilecek bir durum olmasına karşın metropol niteliğindeki kentlerde normal karşılanabilmektedir. Dahası bölgesel iklim koşulları dahi öfke düzeyini etkileyebilmektedir 16 
(meb.gov.tr, 2015). Bunların dışında öfke düzeyi sadece kültürel, bölgesel, dini v.b. farklılıklara göre değil, aynı zamanda diğer demografik değişkenlere göre de farklılık gösterebilmektedir. Bu farklı değişkenlerin öfke düzeyine etkisi araştırmacılar tarafından merak konusu olmuştur. Araştırmacıların; sosyo-ekonomik düzey, meslek, medeni durum, cinsiyet gibi değişkenlere göre öfke düzeyi ile ilgili birçok çalışması göze çarpmaktadır. Bu değişkenler içerisinde cinsiyet, alanyazıdaki çalışmalarda ilk akla gelen değişkenlerden biridir. Ülkemizde toplumun cinsiyetlere yüklediği roller, cinsiyet faktörünün birçok alanda (eğitim, iş, sosyal alanlar vb.) farklı algılanması ve cinsiyetlerin yeterlilikler, benzerlik, farklılıklar gibi kavramlar üzerinden karşılaştırılması bilimsel çalışmalarda cinsiyet değişkeninin sık kullanılmasına neden olmaktadır. Buna bağlı olarak öfke ile ilgili bilimsel çalışmalarda da cinsiyet değişkeni çok sık kullanılmıştır.

Türkiye'de yapılan tezler incelendiğinde; öfke düzeyi ile ilgili yaklaşı 100 çalışmaya ulaşılmıştır. Yapılan çalışmaların neredeyse yarısı cinsiyete göre öfke düzeyini incelemiştir. Birkaç çalışmada cinsiyete göre öfke düzeyinin farklılaştı̆̆ı görülmüştür. Bazı çalışmalarda kadınların öfke düzeyi daha yüksek bulunurken (İmamoğlu, 2003; Kılıç, 2012); bazılarında erkeklerin öfke düzeyinin daha yüksek olduğu saptanmıştır (Gülveren, 2008; Yıldırım, 2006). Bu araştırmaların aksine çalışmaların birçoğunda erkek ve kadınların öfke düzeyleri arasında anlamlı bir fark bulunamamıştır (Genç, 2007; Hoşgör, 2013; Şahin, 2014; Tanış, 2004).

Türkiye'de yapılan tezlerde cinsiyet değişkeninin öfke çalışmalarında yeterince kullanıldığı görülmektedir. Türkiye'deki tezler üzerinde yapılması planlanan bu meta-analiz çalışması "Öfke düzeyi cinsiyete göre değişmekte midir?” sorusuna daha net bir cevap niteliğinde olacaktır. Bu bağlamda öfke ile ilgili yapılacak olan bilimsel çalışmalara katkı sunacağı düşünülmektedir.

Bu meta-analiz çalışmasının amacı Türkiye'de yayınlanan yüksek lisans ve doktora tezlerindeki araştırmalarda öfke düzeyinin cinsiyete ilişkin bulgularını incelemektir. Bu amaç kapsamında aşağıda yer alan soruyu cevaplandırmak için öfke ile ilgili 100 çalışma içerisinden cinsiyet değişkeninin olduğu ve çalışmaya dahil edilebilecek verilere sahip tüm tezler incelenerek toplam 24 çalışma analize dahil edilmiştir.

\section{Yöntem}

Bu araştırmada öfke düzeyine ilişkin Türkiye'de yapılmış tezlerden elde edilen bulgular toplanarak analiz edilmesini amaçlayan Meta-Analiz yöntemi kullanılmıştır (Borenstein, Hedges, Higgins ve Rothstein; 2013). Meta-analiz, belirli bir konuda yapılmış, birbirinden bağımsız, birden çok çalışmanın sonuçlarını birleştirme ve elde edilen araştırma bulgularının istatistiksel analizini yapma yöntemidir (Akgöz vd., 2004).

$\mathrm{Bu}$ araştırmadaki verilere ulaşmak amacıyla Yüksek Öğretim Kurumu'nun resmi internet sitesi üzerinden Türkiye'deki tezleri içeren veri tabanından faydalanılmıştır (yok.gov.tr). İlgili çalışmalara 
ulaşmak için "öfke" ve "anger" anahtar kelimeleri kullanılmıştır. Tarama işlemi Şubat-Nisan 2015 tarihleri arasında gerçekleştirilmiştir. Toplam 217 tez içerisinden öfke düzeyi ile ilgili 101 çalışma tespit edilmiştir. Araştırmada 101 çalışma içerisinden cinsiyet değişkenini kullanan ve analiz sonuçlarını teze dahil eden 24 çalışma kullanılmıştır. Akış diyagramı Şekil-1'de verilmiştir. Araştırmaya sürekli öfkeöfke ifade tarz ölçeğini kullanan tezler dahil edilmiştir. Sadece sürekli öfke verileri dikkate alınmıştır. Buna ek olarak araştırmada kullanılmak üzere cinsiyet değişkenine göre test edilen sürekli öfke (öfke düzeyi) verileri içerisinden kadın ve erkeklerin örneklem sayıları, ortalama puanlar, standart sapma, F, t ve p değerleri kullanılmıştır.
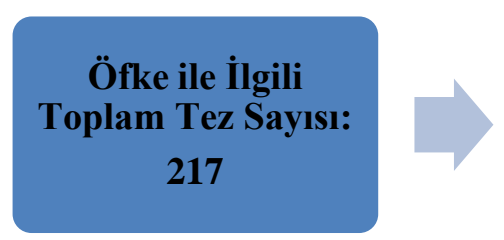
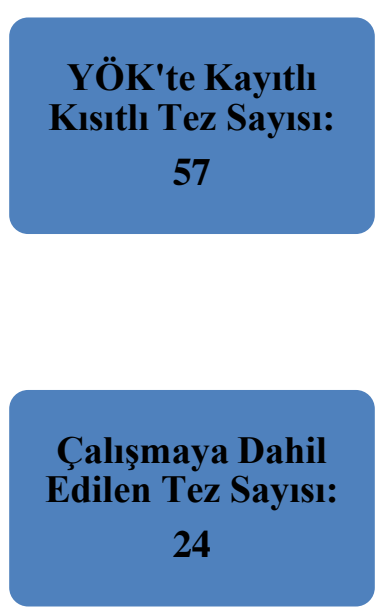
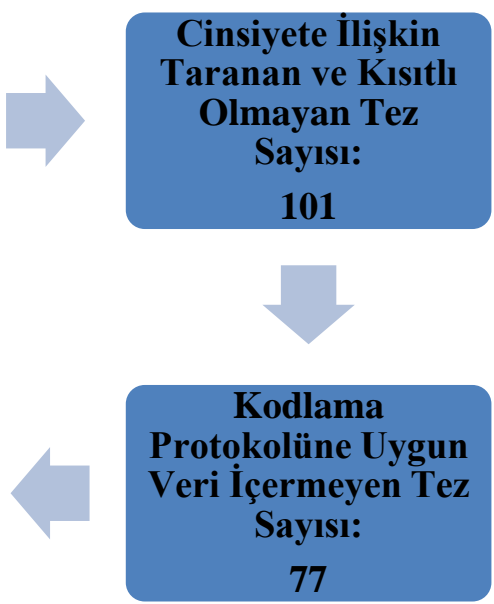

Şekil-1. Literatür taraması sonucu ulaşılan tezler ve araştırmaya dâhil edilmelerine ilişkin akış diyagramı

$\mathrm{Bu}$ çalışmada Standardize Ortalamalar Farkı (SOF) kullanılarak etki büyüklüğü hesaplanmıştır. SOF’u hesaplamak ve olası moderatörlere ulaşabilmek için örneklem büyüklüğü (kadın, erkek), etki büyüklüğünü hesaplamak için t, F ve $X^{2}$ nicel verileri, anlamlılık (p) değerleri veya standart sapma değerleri kullanılmıştır. Bu çalışma için kadın ve erkek kodlanması kadın=1 erkek $=0$ şeklindedir. Pozitif sonuç kadınlar lehine, negatif sonuç ise erkekler lehine bir farkı göstermektedir. Tam ters şekilde kodlanmış bir veriye ulaşıldığında bu çalışmanın kodlama planına dönüşüm yapılmıştır.

Araştırma kapsamındaki 24 tez çalışması 2003-2014 yılları arasında yapılmıştır. Örneklem sayısı 3495'i erkek, 3932'i kadın olmak üzere toplam 7427 bireyi kapsamaktadır. Çalışmaların tamamı Türkiye'de yapılmış olan ve ulaşılabilir tezlerden oluşmaktadır. Dâhil edilen çalışmalarda Sürekli öfkeöfke tarz ölçeği kullanılmıştır. Sadece sürekli öfke boyutu dikkate alınmıştır.

Etki büyüklüğü hesaplamaları Comprehensive Meta-Analysis (Version 2.0) yazılımı (Borenstein, Hedges vd, 2005) kullanılarak yapılmıştır. Hesaplamalar sabit ve rastgele etkiler modelinde yapılııştır. $\mathrm{Bu}$ durum yanı sıra sosyal bilimlerde rastgele etkiler modeli önerilmektedir (Cumming, 2012). Etki büyüklüklerinin heterojenliği Q ve $\mathrm{I}^{2}$ istatistiği kullanılarak değerlendirilmiştir. 
Yayın yanlılığının olup olmadığını test etmek amacıyla Huni grafiği, Orwin Güvenli N Sayısı,

Duval ve Tweedie'nin kırp doldur yöntemi ve Egger testi olmak üzere toplam dört yöntem kullanılmıştır.

\section{Bulgular}

Araştırmaya dahil edilen çalışmalarda yayın yanlılığının olup olmadığını test etmek amacıyla yapılan analiz sonucu Tablo-1'de gösterilmiştir.

Tablo 1. Öznel iyi oluş-cinsiyet için yayın yanlılı̆̆ test sonuçları

\begin{tabular}{|c|c|c|c|c|}
\hline \multirow{2}{*}{$\begin{array}{l}\text { Dahil } \\
\text { Edilen } \\
\text { Çalışma } \\
\text { Sayıs1 }\end{array}$} & \multirow{2}{*}{$\begin{array}{c}\text { Orwin korumalı N Sayısı } \\
\text { “önemsiz” SOF için gerekli } \\
\text { çalışma sayısı }\end{array}$} & \multicolumn{2}{|c|}{$\begin{array}{l}\text { Duval ve Tweedie'nin Kırp } \\
\text { ve doldur yöntemi }\end{array}$} & \multirow{2}{*}{ Egger Testi } \\
\hline & & $\begin{array}{l}\text { Kırpılan } \\
\text { çalışma }\end{array}$ & $\begin{array}{l}\text { SOF Gözlenen } \\
\text { (doldurulan) }\end{array}$ & \\
\hline 24 & 0,01 SOF için 324 & 5 & $-0,02(0,03)$ & $p=0,12$ (çift kuyruk) \\
\hline
\end{tabular}

Tablo 1'e bakıldığında, Orwin's Fail-Safe N 324 olarak hesaplanmıştır. Meta analiz sonucunda bulunan $-0,02$ ortalama etki büyüklüğünün 0,01 düzeyine (trivial), yani neredeyse sifir etki düzeyine ulaşabilmesi için gerekli çalışma sayısı 324 adettir. Hâlbuki dâhil edilen 24 çalışma Türkiye'de bu araştırma sorusuna yönelik yapılmış tüm çalışmalardan dâhil edilme kriterine göre ulaşılabilmiş çalışmaların tamamıdır ve bulunan sonuç dahil edilen çalışmaların 13 katından fazladır. Bunların dışında 324 çalışmaya daha ulaşılmasının olası olmaması, bu sonucun bu meta-analizde yayın yanlılığı olmadığının bir göstergesidir. Duval ve Tweedie'nin kırp ve doldur yöntemi sonucuna göre, 5 emsal çalışma dâhil edildiğinde, meta analiz sonucunda bulunan $-0,02$ ortalama etki büyüklüğünün, 0,03 olarak değiştiği görülmektedir. Bu değişiklik, önemsiz düzeyde olduğu için rapor edilen etki büyüklüğünün daha güvenilir olduğu kabul edilebilir. Diğer bir yayın yanlılığı testi olan Egger testi sonucunun da $(p=0,12)$ anlamlı olmaması, bu meta analizde yayın yanlılığının olmadığının bir diğer göstergesi olarak kabul edilmiştir.

Yayın yanlılığının olasılığını gösteren huni saçılım grafiğinin sonuçları Grafik 1'de gösterilmektedir. Huni saçılım grafiğinde, çalışmaya ait standart hata değeri Y ekseninde, etki büyüklüğü X ekseninde gösterilmektedir. 


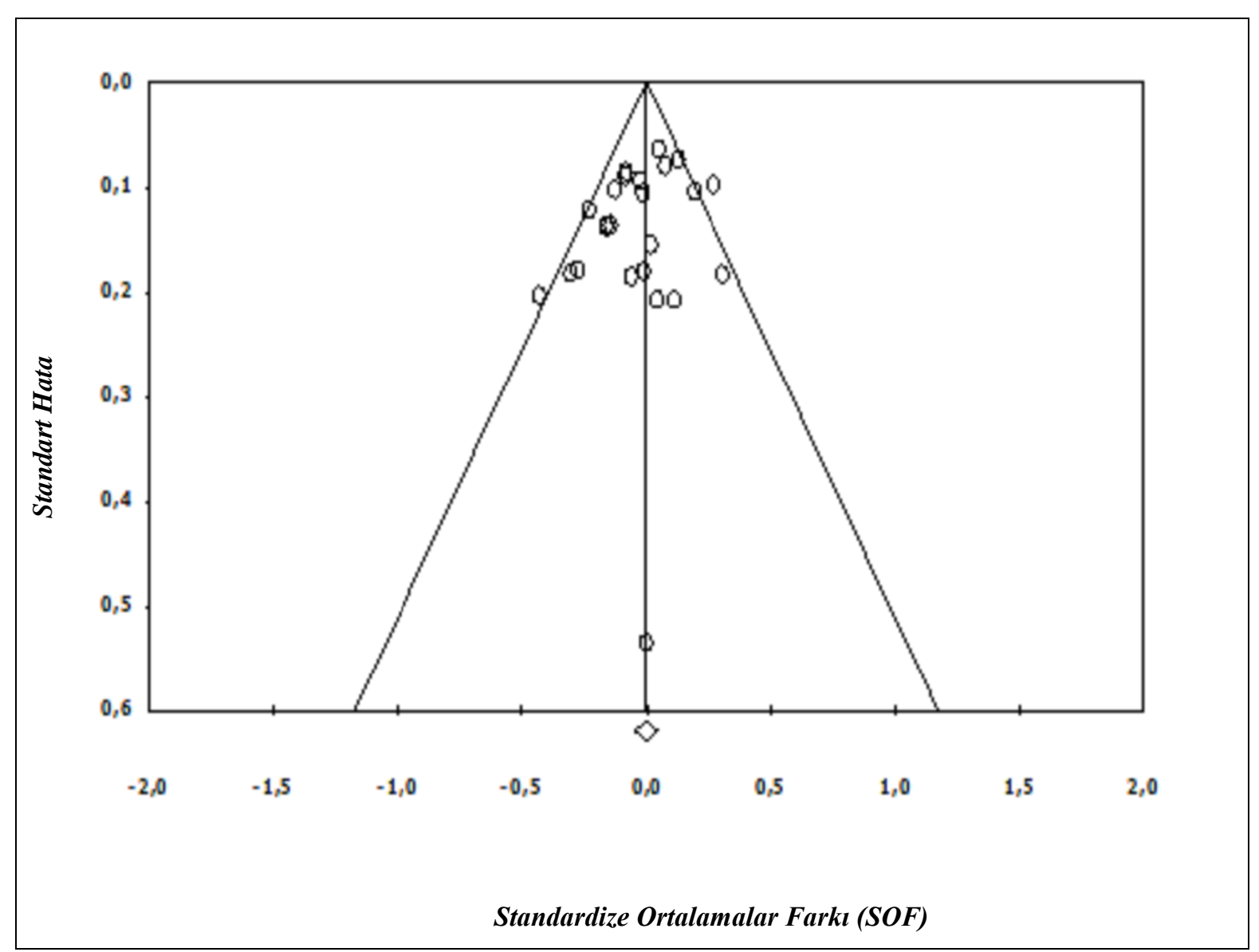

Şekil-2. Öfke Düzeyi Etki Büyüklüğü Verisi İçeren 24 Çalışmanın Huni Saçılımı Grafiği

Şekil 2'de görüldüğü gibi, araştırmaya dâhil edilen 24 çalışma; birleştirilmiş etki büyüklügüne yakın bir konumda ve etki büyüklüğü dikey çizgisinin her iki yanında simetrik olarak yer almaktadır. Yayın yanlılığının olmadığını; 24 çalışmanın simetrik bir şekilde üst bölgede dağıllıyor olması göstermektedir.

\subsection{Cinsiyete İlişkin Veri İçeren Çalışmaların Orman Grafiği}

Çalışmalara ait orman grafiği (forest plot) olan Şekil 2, araştırmaya dâhil edilen ve cinsiyete ait veri içeren 24 çalışmayı toplu hâlde göstermektedir. 
Modds studymane

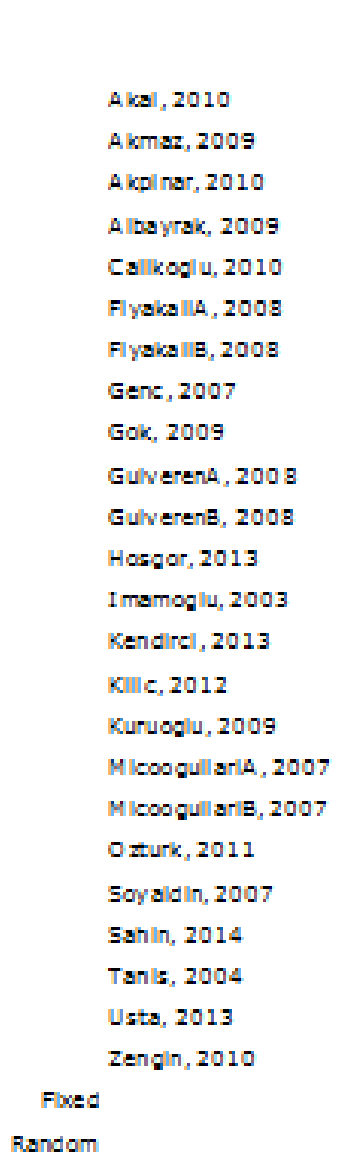

Stddiff

In means p-Value

$-0,276 \quad 0,123$

$0,1110,593$

$\begin{array}{rr}-0,158 & 0,247\end{array}$

$-0,230 \quad 0,060$

$0,310 \quad 0,092$

$\begin{array}{rr}-0,026 & 0,779\end{array}$

$-0,128 \quad 0,213$

$-0,001 \quad 0,999$

$-0,015 \quad 0,887$

$0,042 \quad 0,841$

$-0,430 \quad 0,035$

$-0,143 \quad 0,293$

$0,2710,006$

$0,1280,085$

$0,1930,066$

$-0,160 \quad 0,245$

$-0,305 \quad 0,094$

$\begin{array}{ll}-0,061 & 0,742\end{array}$

$-0,011 \quad 0,952$

$\begin{array}{ll}-0,082 & 0,339\end{array}$

$0,0750,350$

$\begin{array}{ll}0,086 & 0,339\end{array}$

$0,050 \quad 0,436$

$0,019 \quad 0,900$

$-0,001 \quad 0,951$

$-0,018 \quad 0,580$

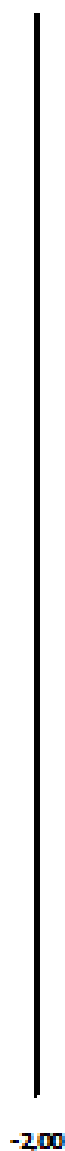

$-2,00$ stddiff in moans and $95 \%$ a

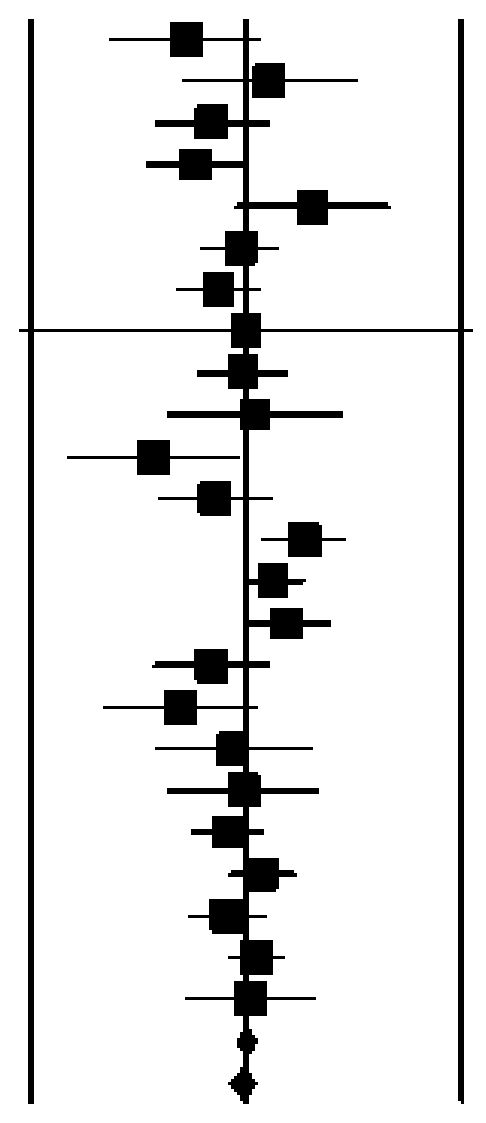

$1, \infty$

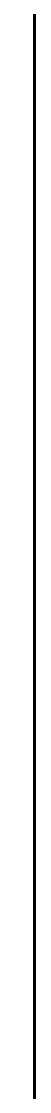

2,00

\section{ERKEK}

KADIN

Şekil-3. Cinsiyet değişkenine göre öfke etki büyüklükleri orman grafiğ

Şekil-3 incelendiğinde erkekler lehine bir farkın olabileceği ancak bu farkın etkisizlik çizgisine çok yakın olduğu söylenebilir

\subsection{Cinsiyete ilişkin etki büyüklüğü temel analiz bulguları}

$\mathrm{Bu}$ meta-analiz çalışmasının temel amacı öfke düzeyine göre kadın ve erkek arasında anlamlı bir farklılığın olup olmadığının incelenmesidir. Aşağıda, etki büyüklüğü dağılımının homojenlik testinin ve sabit etki modeli ve rastgele etkiler modeline göre yapılan analizlerin sonuçları Tablo 2'de gösterilmiştir. 


\begin{tabular}{|c|c|c|c|c|c|c|c|c|c|}
\hline $\begin{array}{c}\text { Model } \\
\text { Türü }\end{array}$ & $\mathbf{K}$ & $\mathbf{n}$ & $\begin{array}{c}\text { Cohen's } \\
d\end{array}$ & SE & $\mathbf{P}$ & $95 \%$ CI & $\mathbf{Q}$ & $\mathbf{p}$ & $\mathbf{I}^{2}$ \\
\hline SEM & \multirow{2}{*}{24} & \multirow{2}{*}{7427} & 0,00 & 0,02 & 0,95 & $-0,05 ; 0,04$ & \multirow{2}{*}{39,11} & \multirow{2}{*}{0,02} & \multirow{2}{*}{41,19} \\
\hline REM & & & $-0,02$ & 0,03 & 0,57 & $-0,08 ; 0,05$ & & & \\
\hline
\end{tabular}

Notlar: k=çalışma sayısı. $\mathrm{n}=$ örneklem. $\mathrm{SE}=$ Standart Hata. $\mathrm{CI}=$ Güven Aralığı. SEM=Sabit Etki Modeli. REM=Rastgele Etkiler Modeli.

Tablo 2'de elde edilen bulgulara göre; araştırmaya dahil edilen 24 tez çalışmasının sabit etki modeline (SEM) göre ortalama etki büyüklüğü değeri 0,00; ortalama etki büyüklügünün standart hatas1 (SE) 0,02 ; ortalama etki büyüklügünün güven aralığı alt sınırı $-0,05$ ve üst sinırının 0,04 olduğu saptanmıştır. Dahil edilen çalışmaların homojenlik testi $\mathrm{Q}=39,11$ olarak tespit edilmiştir. Buna ek olarak $\mathrm{p}=0.02(\mathrm{p}<.05)$ olarak hesaplandığı için etki büyüklüklerinin dağılımına ait homojenliğin yokluk hipotezi reddedilmiştir. Başka bir ifade ile etki büyüklükleri dağılımının heterojen bir yapıda olduğu saptanmıştır. Etki büyüklüğüne ilişkin toplam varyansın oranını gösteren $I^{2}$; Petticrew ve Roberts'a (2006) göre Q istatistiğinin tanımlayıcısı olarak geliştirilmiş ve heterojenliğe ilişkin daha net sonuçlar ortaya koymaktadır. Ayrıca $\mathrm{I}^{2}$ analizi; Q istatistiğinde olduğu gibi çalışma sayısından etkilenmemektedir. . $I^{2}$ nin yorumlanmasında ise $\% 25$ düşük düzeyde heterojenliği, \% 50 orta düzeyde heterojenliği ve \% 75 yüksek düzeyde heterojenliği göstermektedir (Cooper ve ark., 2009). Cinsiyet için, sabit etki modeline göre ortalama etki büyüklüğü değeri için $I^{2}$ değeri \% 41,19 ile orta düzey heterojenliği göstermektedir. Heterojenliğe ilişkin elde edilen istatistiksel veriler 1şığında; rastgele etkiler modeline göre hesaplanan ortalama etki büyüklüğü dikkate alınmıştır. Rastgele etkiler modeline göre ortalama etki büyüklügünün standart hatası 0,03 , ortalama etki büyüklüğünün güven aralığg alt sınırı - 0,08 , üst sınırı 0,05 ve ortalama etki büyüklüğü değeri $-0,02$ olarak hesaplanmıştır. Bu durum öfke düzeyinin erkekler lehine olduğu yönünde bulgulara işaret etmektedir. Ancak ilgili etki büyüklüğü değeri 0,20'den küçük olduğu için Cohen'in sınıflandırmasına göre düşük düzeyin altında yani önemsiz bir etkiye sahip olduğu saptanmıştır (Cohen, 1988). Thalheimer ve Cook (2002)'a ait sınıflandırmaya göre ise önemsiz düzeyde $(-0,15-0,15)$ bir etki büyüklüğüdür. Son olarak söz konusu çalışma Lipsey'in sınıflandırmasına göre 0,15 'den daha az olduğundan düşük düzeyin de altında bir etki büyüklüğü sahiptir.

\section{Sonuç ve Tartışma}

Yapılan araştırmaya göre Türkiye'de cinsiyete ilişkin yeterince öfke düzeyi ilgili tez çalışması olduğu kanısına varılmıştır. Bu duruma bağlı olarak Türkiye'de yapılan tezler üzerinden yapılan bu meta-analiz çalışması, cinsiyete göre öfke düzeyinin farklılaşıp farklılaşmadığına 1şık tutabilmek amacıyla yapılmıştır. Çalışmadaki bulgular cinsiyete ilişkin öfke düzeyi puanına sahip 24 tez 
çalışmasındaki verilere göre değerlendirilmiştir. Araştırmaya dahil edilen çalışmaların örneklem büyüklüğü toplamda 7427 bireydir. Örneklem; 3495 (\%47.05) erkek, 3932 (\%52.95) kadın katılımcıdan oluşmaktadır.

Araştırmada; yayın yanlılığının olup olmadığını test etmek amacıyla Huni grafiği, Orwin Güvenli N Sayıs1, Duval ve Tweedie'nin kırp doldur yöntemi ve Egger testi; ortalama etki büyüklüğü, homojenliği, anlamlı fark olup olmadığını ve farkın kimin lehine olduğunu test etmek amacıyla da temel analiz (Cohen' d, CI, Q, p ve I² değerleri için) yapılmıştır. Elde edilen bulgulara göre öfke düzeyi cinsiyet değişkenine göre farklılaşmamaktadır. İstatistiksel sonuç erkekler lehine çıkmış olsa da anlamsız düzeyde bir değere sahiptir.

Türkiye'de yapılan alanyazı taramasına göre elde edilen sonucu destekleyen ya da desteklemeyen bir çalışmaya ulaşılamamıştır. Yapılan çalışmaların öfke kontrolü ya da öfke kontrolünün tedavi tekniklerine yönelik olduğu saptanmıştır (Hamamcı ve Türk, 2014). Buna ek olarak yurtdışında yapılan çalışmalar da öfke kontrolü ya da öfke kontrolünün tedavi tekniklerinin işlevselliğine ilişkin bulgular içermektedir (Beck ve Fernandez, 1998; Sukhodolsky, Kassinove ve Gorman, 2001; Gansle, 2005). Bu araştırmaya dahil edilen 24 çalışmanın 21 'inde erkek ya da kadınların lehine anlamlı bir sonuca rastlanmamıştır. Bunların aksine Gülveren (2008) ve Albayrak'ın (2009) yapmış olduğu çalışmaya göre kadınların öfke düzeyleri erkeklerden daha düşüktür. İmamoğlu (2003) ve Kılıç'ın (2012) yapmış olduğu çalışmaya göre ise kadınların öfke düzeyi erkeklerden daha yüksektir.

Araştırmaya dahil edilen çalışmalar dikkate alındığında; birçok çalışmada öfke düzeyinin cinsiyete göre değişmediği ve cinsiyetler arası anlamlı fark çıkan çalışma sayısının da nicelik açısından eşit olduğu görülmektedir. Bu araştırmada yapılan meta analiz bulguları, Türkiye'de yapılan cinsiyete göre öfke düzeyi ile ilgili tez çalışmalarını yordayıcı nitelikte olup, bu çalışmadaki bulgularla aynı doğrultuda olduğu düşünülebilir.

\section{5. Öneriler}

$\mathrm{Bu}$ araştırma sadece öfke düzeyinin cinsiyete ilişkin verileri üzerinden bir meta-analiz çalışması olarak tasarlanmıştır. Aynı konu kapsamında farklı değişkenler üzerinden de bir meta-analiz çalışması yapılabilir. Türkiye'de öfke düzeyi ile ilgili makaleler, sunum vb. bilimsel çalışmalar da taranarak bir çalışma daha yapılabilir. Yurtiçi ve yurtdışında yapılan meta-analiz çalışmalarının birçoğu öfke kontrolü ve tedavi tekniklerinin işlevselliği üzerine olduğu görülmektedir. Bu yüzden öfke düzeyi ile ilgili yurtiçi ve yurtdışı çalışmalarının da dahil edildiği meta-analiz çalışmaları da önerilebilir. 


\section{Kaynakça}

*Yıldız imi ile işaretlenmiş çalışmalar meta-analize dâhil edilen çalışmalardır.

*Akal, A. (2010) Üniversite Öğrencilerinde Algllanan Sosyal Destek İle Öfke İfade Biçimleri Arasındaki İlişkinin İncelenmesi. Yayınlanmamış Yüksek lisans Tezi. Maltepe Üniversitesi, Sosyal Bilimler Enst., İstanbul.

Akgöz, S., Ercan, İ., Kan, İ. (2004) Meta-Analiz. Uludağ Üniversitesi Tip Fakültesi Dergisi, 30(2), 107-112.

*Akmaz, N. (2009) Eğitim Yöneticilerinin Bağlanma Stilleri ve Sürekli ve Öfke İfade Tarzları Arasındaki IIlişkinin İncelenmesi. Yayınlanmamış Yüksek lisans Tezi. Yeditepe Üniversitesi, Sosyal Bil. Ens., İstanbul.

*Akpınar, F. (2010) Borderline Kişilik Bozukluğu Olan Bireylerin Öfke Tarzları ve Saldırganlık Davranışı Üzerine Bir İnceleme. Yayınlanmamış Yüksek lisans Tezi. Maltepe Üniversitesi, Sosyal Bilimler Enstitüsü, İstanbul.

*Albayrak, B. (2009) Ergenlerde Öfke Ifade Tarzı ile Kan Basıncı Arasındaki Iliş̧ki. Yayınlanmamış Yükseklisans Tezi. İstanbul Üniversitesi, Sağlık Bilimleri Enstitüsü, İstanbul.

Archer, J. (2004). Sex Differences in Aggression in Real-World Settings: A Meta-Analytic Review. Rewiew of General Psychology, 8(4), 291-322.

Beck, R. ve Fernandez, E. (1998). Cognitive-Behavioral Therapy in the Treatment of Anger: A Meta-Analysis. Cognitive Therapy and Research, 22(1), 63-74.

Bedell, J. R. and Lennox, S. S. (1997). Handbook for communication and problem solving skills training- a cognitive - behavioral approach. New York: John Wiley Sons Inc.

Borenstein, M., Hedges, L., Higgins, J., \& Rothstein, H. (2005). Comprehensive Meta-Analysis Version 2. Englewood, NJ: Biostat.

Cohen, J. (1988). Statistical power analysis for the behavioral sciences (2nd ed.). New Jersey: Lawrence Erlbaum Associates, Inc. Retrieved from http://books.google.com.tr/books?id=T10N2IRAO9oC\&printsec $=\mathrm{f} \mathrm{r}$ o $\mathrm{n} \mathrm{t}$

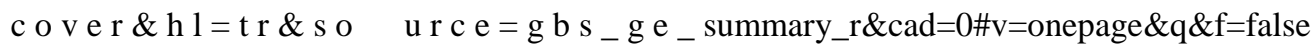

Cumming, G. (2012). Understanding the new statistics. New York: Routledge, Taylor and Francis Group.

*Çalıkoğlu, T. (2010). Lise Öğrenimine Devam Eden Ailesinin Yanında Yaşayan Öğrencilerle, Yetisstirme Yurdunda Yaşayan Öğrencilerin Çatışma Çözme Davranışı ile Öfke Ifade Stillerinin Karşslaştırılması. Yayınlanmamış Yükseklisans Tezi. Maltepe Üniversitesi. İstanbul.

Demir, Y. ve Kumcağız, H. (2015). Öğrencilerin anne-babalarını algılama biçimleri ve şiddete eğilimleri. International Periodical For The Languages, Literature and History of Turkish or Turkic, 10(12), 221-234.

Demir, Y., \& Kutlu, M. (2016). Üniversite öğrencilerinde sosyal etkileşim kaygısı ile mutluluk arasındaki ilişki: yalnızlı̆̆ın aracı rolü. Gazi Üniversitesi Gazi Eğitim Fakültesi Dergisi, 36(1), 195-210.

Deniz, E. (2011). Erken Çocukluk Döneminde Gelişim. Ankara: Ertem Basım Ltd. Şti. s.196.

*Fiyakalı, N. C. (2008) Anne Babası Boşanmışve Boşanmamış Lise Öğrencilerinin Sürekli Öfke Düzeyleri ve Öfke Ifade Tarzlarının Bazı Değişkenler Açısından Karşslaşstırılması. Yayınlanmamış Yükseklisans Tezi. Pamukkale Üniversitesi. Sosyal Bil. Ens., Denizli.

Gallo LC, Smith TW. (1999) Patterns of hostility and social support: Conceptualizing psychosocial risk factors as characteristics of the person and the environment. Journal of Research in Personality. 33, 281-310. 
Gansle, K. A. (2005). The Effectiveness of School-Based Anger Intervention and Programs: A Meta-Analysis. Journal of School Psychology, 43, 321-341.

*Genç, H. (2007) Grupla Öfke Denetimi Ĕ̆itiminin Lise 9. Sınıf Öğrencilerinin Sürekli Öfke Düzeylerine Etkisi. Dokuz Eylül Üniversitesi, Eğitim Bilimler Enstitüsü, İzmir.

*Gök, M. (2009) Aile İçi Şiddet Öfke Iffade Tarzları Arasındaki İlişkinin Incelenmesi. Yayınlanmamış Yükseklisans Tezi. Çukurova Üniversitesi, Sosyal Bilimler Ens., Adana.

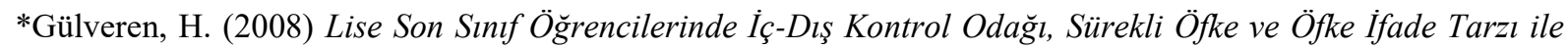
Zeka Arasındaki İlişkinin İncelenmesi. Yayınlanmamış Yükseklisans Tezi. Maltepe Üniversitesi, Sosyal Bilimler Enstitüsü, İstanbul.

Hamamcı, Z. ve Türk, F. (2014). Bilişsel Davranışçı Yaklaşıma Dayalı Öfke Kontrolü Programlarının Ergenlerin Öfke Düzeyleri Üzerindeki Etkileri: Bir Meta-Analiz Çalışması. V. Ulusal Psikolojik Danışmanlık ve Rehberlik Uygulama Kongresi Bildiri Özet Kitapçı̆̆l, s.34.

*Hoşgör, E. T. (2013) Evli Çiftlerin Öfke Iffade Tarzları ile Evlilik Uyumunun İncelenmesi. Yayınlanmamış Yükseklisans Tezi. Dokuz Eylül Üniversitesi, Sosyal Bilimler Enstitüsü, İzmir.

Howells, K., Day, A. (2003) Readiness for anger management. Clinical and Theoretical Issues. Clinical Psychology Reiew. Sayl: 23, 319-337.

http://mebk12.meb.gov.tr/meb_iys_dosyalar/65/01/972207/icerikler/ofke_568882.html, Erişim Tarihi: 10.05 .2015 .

http://www.tdk.gov.tr/index.php?option=com_gts\&arama=gts\&guid=TDK.GTS.555a8a3f028ed1.22607514, Erişim Tarihi: 10.05.2015.

*İmamoğlu, S. (2003) Öğretmen Adaylarının Öfke ve Öfke İfade Tarzları ile Bağlanma Stilleri Arasındaki İlişkinin Incelenmesi. Yayınlanmamış Yükseklisans Tezi. Marmara Üniversitesi, Eğitim Bilimler Enstitüsü, İstanbul.

Karslı, N. (2012). Dindarlık ve Öfke Kontrolü İlişkisi Üzerine Tecrübi Bir Araştırma. Ekev Akademi Dergisi, 16, $50,57-70$.

*Kendirci, A. (2013) Evli Bireylerin Öfke İfade Tarzlarl ve Şiddet Sorumluluğunun İncelenmesi. Yayınlanmamış Yükseklisans Tezi. Gaziosmanpaşa Üniversitesi, Eğitim Bilimleri Enstitüsü, Eskişehir.

*Kılıç, M. (2012) Üniversite Öğrencilerinin Algıladıkları Ebeveyn Kabul-Reddinin Öfke Ífade Tarzı ve Depresif Belirtiler ile İlişkisinin Ebeveyn Kabul ve Reddi Kuramı Çerçevesinde Incelenmesi. Yayınlanmamış Yükseklisans Tezi. Hacettepe Üniversitesi, Sosyal Bilimleri Enstitüsü, Ankara.

*Kuruoğlu, D. S. (2009) Üniversite Öğrencilerinin Sürekli Öfke Düzeyleri, Öfke İfade Tarzları ile Obsesif Kompülsif Semptomları Arasındaki İlişki. Yayınlanmamış Yükseklisans Tezi. Maltepe Üniversitesi, Sosyal Bilimler Enstitüsü, İstanbul.

*Miçooğulları, B. O. (2007) Özel Yetenek ve Öss Sinavı ile Öğrenci Alan Öğretmenlik Bölümlerinde Öğrenim Gören Öğretmen Adaylarının Sürekli Öfke-Öfke Tarz Özelliklerinin Karşılaştırılması. Yayınlanmamış Yükseklisans Tezi. Abant İzzet Baysal Üniversitesi, Sosyal Bil. Enst., Bolu.

Ozmen, F., Akuzum, C., Zincirli, M., \& Selcuk, G. (2016). The communication barriers between teachers and parents in primary schools. Eurasian Journal of Educational Research, 66, 26-46 
*Öztürk, T. (2011) İnfertilitede Anksiyete, Depresyon, Stresle Başa Çıkma Tutumlarl, Sürekli Öfke ve Öfke İfade Tarzı Açısından Cinsiyet Farklılıkları. Tıpta Uzmanlık Tezi. Bakırköy Ruh Sağlığı ve Sinir Hastalıkları Eğitim ve Araştırma Hastanesi, 1. Psikiyatri Kliniği, İstanbul.

Petticrew, M., \& Roberts, H. (2006). Systematic reviews in the social sciences. MA-USA: Blackwell Publishers Ltd.

*Soyaldın, S. Z. (2007) Orta Öğretim Öğrencilerinin Öfke İfade Tarzları ile Mizah Tarzları Arasındaki İlişsinin İncelenmesi. Yayınlanmamış Yükseklisans Tezi. Mersin Üniversitesi, Sosyal Bilimler Enst., Mersin.

Soysal, A. Ş., Can, H. ve Kılıç, K. M. (2009). Üniversite Öğrencilerinde A Tipi Davranış Örüntüsü ile Öfke İfade Arasındaki İlişkinin Analizi ve Cinsiyetler Açısından Karşılaştırılması. Klinik Psikiyatri, 12, 61-67.

Sukhodolsky, D G., Kassinove, H. ve Gorman B. S. (2004). Cognitive-Behavioral Therapy for Anger in Children and Adolescents: A meta-analysis. Aggression and Violent Behavior, 9, 247-269.

*Şahin, A. (2014) Spor Yapan ve Yapmayan Bedensel Engelli Bireylerin Öfke Ifade Tarzlarının Araştırlması. Yayınlanmamış Doktora Tezi. Gazi Üniversitesi, Eğitim Bilimleri Enst., Ankara.

*Tanış, Z. İ. (2004) Yetişkinlerde Bağlanma Stilleri ve Öfke Tarzları Arasındaki İlişkinin İncelenmesi. Yayınlanmamış Yükseklisans Tezi. Haliç Üniversitesi, Sosyal Bilimler Enst., İstanbul.

Thalheimer, W., \& Cook, S. (2002). How to calculate effect sizes from published research articles: A simplified methodology. Retrieved from http://work-learning.com/effect_sizes.htm

*Usta, A. (2013) Lise Öğrencilerinin Öfke Düzeyleri ile Siber Zorbalık Düzeyleri Arasındaki İlişkinin İncelenmesi. Yayınlanmamış Yükseklisans Tezi. Ondokuz Mayıs Üniversitesi, Eğitim Bilimleri Enst., Samsun.

Yavuz, C. (2019). The Relationships among Attitude towards Sports, Loneliness and Happiness in Adolescents. Universal Journal of Educational Research, 7(3), 790-796.

*Zengin, (2010) Bireysel Mücadele Sporlarındaki (Taekwondo, Judo, Güreş) Elit Sporcuların Kişilik Özellikleri ile Öfke Düzeyleri Arasındaki İlişkinin İncelenmesi. Yayınlanmamış Yükseklisans Tezi. Tezi Gazi Üniversitesi, Sağlık Bilimleri Enst., Ankara. 


\section{Extended Summary}

Since the beginning of human history in all societies; there are numerous stories, legends, proverbs and verbal sources about the damages of anger to the individuals and their environment. Although in each culture the verbal and written sources about the anger come with their own unique approaches, the high level of anger is generally perceived as negative. In addition, many religious beliefs tried to explain that anger is a negative situation, which harms person himself and also his environment, and it has a negative effect on individuals' bilateral relations. Despite all these studies, intervention programs, trainings, religious doctrines and laws, the problem of anger has continued in various ways for centuries.

According to Bedell and Lennox (1997), individuals become angry to meet their existing expectations when their expectations are not met. Anger is a feeling that reduces social interaction and affects the quality of social interaction negatively (Gallo \& Smith, 1999). Usta (2013) describes anger as when individuals' requests are prevented, they feel inadequate, worthless and etc. so consequently they show a threatening reaction to those who try to prevent and limit their actions. According to TDK (2015) anger is defined as a response to the aggression, anger, rage and wrath in the face of intimidation, threat and offence. According to Deniz (2011), tapping and anger crises are common expressions of anger in play age and infancy, but being prone to violence in adolescence may also change according to perceived parental attitudes (Demir and Kumcağız, 2015). Inadequate social interaction opportunities may also affect individuals' emotions negatively (Yavuz, 2019). In addition, behaviors like kicking, shouting and breathlessness indicate the level of anger attacks. When the definition of anger and its onset were examined; it can be said that anger is a natural emotion in the life process (Howells and Day, 2003). However, its level and continuity may cause problems for the person and his/her environment. As there are internal reasons that cause anger such as frustration, guilt and shame, low self-esteem, jealousy, frustration, bad memories and competition; there are also external causes like not cared for, being threatened, attacked, deceived and seen as worthless, permanent diseases, alcohol and drugs, sexual harassment, and lastly death (Karsli, 2012; Ozmen, Akuzum, Zincirli and Selcuk, 2016).

The aim of this meta-analysis of published research studies in master's and doctoral theses in Turkey is to analyze the findings of gender related anger level. Thus, in order to answer the following question, a total of 24 studies were included in this analysis out of 100 studies about anger that contains gender variable and all the theses with the data that could be appropriate for the study.

Methods and Findings

This study aims to analyze the collected data obtained from theses in Turkey that are conducted on the anger level by using meta-analysis method (Borenstein, Hedges, Higgins and Rothstein, 2013). Meta- 
analysis is a method of combining the results of multiple studies and making statistical analysis of the obtained research findings (Akgöz et al., 2004).

This research was utilized in order to achieve the data from the database that contains the thesis in Turkey via the official web site of the Institution of Higher Education (yok.gov.tr). In order to reach the related studies, "öfke" and "anger" keywords were used. The screening was carried out between February and April 2015. 101 out of 217 theses related to anger level were determined. In this research, 24 studies were used which included gender variable and the findings of the analysis in their theses. The flow diagram is given in Figure-1. The sample size of the studies included in the study is 7427 individuals in total. Sample is consisted of 3495 males (47.05\%) and 3932 females (52.95\%). Theses using state anger - anger expression style scale were included in the study. Only state anger data were taken into consideration. In addition, the sample numbers, mean scores, standard deviation, $\mathrm{F}, \mathrm{t}$ and $\mathrm{p}$ values of the men and women were used in the study to determine the state anger (anger level) which is tested based on gender.

According to the findings; the effect size value is less than 0,20 for gender according to Cohen's classification so it has been found to have a minor effect (Cohen, 1988). According to the classification of Thalheimer and Cook (2002), it is an insignificant effect size $(-0,15-0,15)$. Finally, as the study is less than 0.15 according to Lipsey's classification and it has an effect size even below the low level.

\section{Discussion and Conclusion}

According to the results there is neither support nor rejection for this study according to the literature in Turkey. Researches are mostly found to be directed towards anger control or anger control treatment techniques (Hamamcı and Türk, 2014). In addition, studies conducted abroad also include findings on anger control and the functionality of anger control treatment techniques (Beck and Fernandez, 1998; Sukhodolsky, Kassinove and Gorman, 2001; Gansle, 2005). In 21 of the 24 studies included in this study, no significant result was found in favor of men or women. In contrast, Gülveren (2008) and Albayrak (2009) reported that women's anger levels were lower than men. According to the study conducted by İmamoğlu (2003) and Kılıç (2012), anger level for women is higher than men.

Considering the studies included in the research; in many studies anger levels did not change according to gender and the number of studies showing significant difference between genders was equal in terms of quantity. Meta-analysis findings reached out in this research are predictive for the studies in Turkey conducted on anger level as related to gender. Lastly meta-analysis findings may be considered in the same direction with the study findings. 